\title{
Dyspnea And Outcome Expectations Are Associated With Physical Activity In Persons With Pneumoconiosis: A Cross-Sectional Study
}

\section{Tomohiro kawaji}

Asahi Rosai Hospital

\section{Takashi Hasegawa}

Nagoya University

Yasushi Uchiyama ( $\nabla$ uchiyama@met.nagoya-u.ac.jp )

Nagoya University

\section{Research Article}

Keywords: physical activity, pneumoconiosis, outcome expectations, dyspnea, chronic respiratory disease, pulmonary rehabilitation

Posted Date: December 13th, 2021

DOI: https://doi.org/10.21203/rs.3.rs-1096378/v1

License: (a) (1) This work is licensed under a Creative Commons Attribution 4.0 International License. Read Full License 


\section{Abstract}

Background: There are various reports on factors associated with physical activity in patients with chronic respiratory diseases. However, there are no studies on the relationship between physical activity and psychological or environmental factors. In this study, we investigated the relationship between physical activity and psychological and environmental factors using questionnaires for patients with pneumoconiosis.

Methods: The present study was a cross-sectional study of patients with pneumoconiosis who underwent pneumoconiosis health examination in 2019. A self-administered questionnaire was used to conduct the study. Physical activity was evaluated using the International Physical Activity Questionnaire, and subjective symptoms (dyspnea and quality of life [QOL]), environmental factors (environment around home and life space), psychological factors (depression, stage of change, self-efficacy, decisional balance, and outcome expectations), and others (e.g., experience with pulmonary rehabilitation) were investigated.

Results: The number of respondents in the study was 185 (men: 171, women: 14). Age, dyspnea, stage of change, self-efficacy, outcome expectations, QOL, depression, decisional balance, and life space were significantly correlated with physical activity. In the multivariate analysis, outcome expectations and dyspnea were extracted as independent factors. In the path analysis, outcome expectations and dyspnea had a direct influence on physical activity. Dyspnea directly impacted not only physical activity but also outcome expectations, stage of change, QOL, life space, and depression.

Conclusions: Dyspnea and outcome expectations were associated with physical activity in patients with pneumoconiosis. To improve the physical activity of patients with pneumoconiosis, it is necessary not only to improve dyspnea but also to promote an understanding of physical activity.

\section{Background}

Pneumoconiosis is a disease characterized by diffuse fibrosis of the lungs and is a typical work-related respiratory disease [1]. In Japan, pneumoconiosis is prevented and managed in accordance with the Pneumoconiosis Law [2]. In compliance with the provisions of the Pneumoconiosis Law, workers with occupational dust exposure, either currently or in the past, shall be subject to health supervision based on classification within a pneumoconiosis supervision class (Class I to IV). The Japanese classification for the supervision of pneumoconiosis classifies workers affected by pneumoconiosis into Class II or higher. Individuals in Class II or higher can still undergo pneumoconiosis health management after retirement [2]. Pneumoconiosis cannot be completely cured [1]; therefore, interventions, such as pulmonary rehabilitation, are performed based on the symptoms.

Chronic respiratory diseases (CRDs), such as chronic obstructive pulmonary disease (COPD) and interstitial pneumonia (IP), have been reported to have systemic comorbidities in addition to respiratory symptoms. These include muscle weakness, exercise intolerance, and depression [3]. Based on these 
reports, pulmonary rehabilitation has been proven to be effective [3]. It has also been reported that physical activity (PA) decreases in patients with CRD [3, 4]. PA has been reported to be the strongest predictor of life expectancy in these patients compared to other factors such as respiratory function and dyspnea $[5,6]$. Therefore, improving the PA is one of the fundamental goals of pulmonary rehabilitation [7]. However, it has not been proven that pulmonary rehabilitation improves PA, and an effective method for improving PA has not yet been established. This is believed to be partly due to the lack of clarity regarding the factors that influence PA in patients with CRD [8].

Factors influencing PA have been studied in healthy elderly individuals and patients with chronic diseases. In healthy elderly persons, it is believed that physical, social, environmental, and psychological factors interact in a complex, multidimensional manner $[9,10]$. It has been reported that in addition to factors similar to those in healthy elderly people, there are also disease-specific factors in patients with chronic diseases $[11,12]$.

Interventions focusing on psychological factors have been reported to be effective in improving PA in healthy elderly people and patients with diabetes. One of these methods is the transtheoretical model (TTM). TTM consists of stages of change, self-efficacy (SE), decisional balance (DB), and outcome expectations $(\mathrm{OE})$, and is a method of intervention tailored to each individual's readiness for behavior change [13]. Moreover, it has been reported that TTM is effective in improving PA in healthy elderly persons and patients with chronic disease [14-16]. For pulmonary diseases, most studies on factors related to PA in patients with CRD have been conducted in patients with COPD. Many factors have been reported to be associated with COPD, including personal factors such as age, education, and drinking history; physical factors such as body mass index, and systemic inflammation; and respiratory factors including hyperinflation, respiratory function, and dyspnea [17]. However, few studies have examined psychological and environmental factors. As a result, there is no evidence regarding the critical factors impacting PA in patients with CRD. Therefore, this study aimed to clarify the psychological and environmental factors related to PA in patients with pneumoconiosis.

\section{Methods}

\section{Study design and participants}

This was a cross-sectional study. We conducted the research using a mailed questionnaire. The subjects were 500 patients with pneumoconiosis scheduled to undergo a pneumoconiosis health examination at the Asahi Rosai Hospital.

Subjects were excluded if they had a Mini-Mental State Examination score $\leq 22$ or were contraindicated for pulmonary rehabilitation according to Japanese guidelines (heart disease, uncontrolled hypertension, acute systemic disease and fever, severe renal/liver dysfunction/orthopedic disease/mental illness, recent pulmonary infarction/acute pulmonary heart disease, and severe pulmonary hypertension). Participants with COPD, interstitial pneumonia, and asthma were excluded from the study. 
The study was approved by the Bioethics Committee of Nagoya University (approval number: 18-515) and the Ethics Committee of Asahi Rosai Hospital (2019.3). Written informed consent was obtained from all patients.

\section{Measurements}

\section{Demographics, personal factors, and subjective symptoms}

Participant characteristics, including age, sex, and pneumoconiosis supervision, were recorded. We also investigated the experience of pulmonary rehabilitation, recognition of pulmonary rehabilitation, and smoking history. Pulmonary rehabilitation recognition was evaluated if the participants knew about pulmonary rehabilitation, using a five-point scale. For smoking history, the presence, number of years, and number of cigarettes smoked were investigated, and the Brinkman index (BI) was calculated. We evaluated dyspnea and quality of life in these patients. We used the modified Medical Research Council (mMRC) dyspnea scale to assess the degree of dyspnea in daily life [18]. Quality of life (QOL) was assessed using the Japanese version of the COPD Assessment Test (CAT). The total points were calculated according to the guidelines [19].

\section{Physical activity}

PA was evaluated using the Japanese version of the International Physical Activity Questionnaire (IPAQ) short form. We calculated the MET-Minutes/ week according to the guidelines. In addition, we divided the data into categories (low/moderate/high) based on the guidelines [20].

\section{Psychological factors}

We examined depression as a psychological factor. Further, based on the theory of TTM, the stages of change, SE, DB, and OE were researched. The stage of change was used to assess the performance of PA and readiness for behavior change. The stage of change for PA was evaluated at five levels (precontemplation, contemplation, preparation, action, and maintenance) [13].

SE was used to assess self-confidence in PA in a variety of situations. SE for PA was evaluated based on six items (negative emotions, making excuses, exercising alone, accessing exercise equipment, interference from others, and weather). Each item was evaluated on a five-point scale, and the total score was calculated [21].

DB was used to investigate the extent to which the subject felt the benefits and disadvantages of PA. DB for PA was evaluated based on ten items. Each item was assessed on a five-point scale and the total score was calculated [22].

OE was used to evaluate expectations and an understanding of the benefits of PA. The OE for PA involved nine items. Each item was rated on a five-point scale. The total score was then calculated [23].

\section{Environmental factors}


We investigated the environment around the home and a range of activities of daily life. The relationship between the environment around the home and PA was evaluated using the Japanese version of the IPAQ-Environment (IPAQ-E) [24]. The total points were calculated according to the guidelines. The range of activities of daily life was assessed using the Life-Space Assessment (LSA) tool [25]. The total points were calculated according to the guidelines.

\section{Statistical analyses}

Statistical analyses were performed using SPSS software (version 26.0 for Windows; IBM Corporation, Armonk, NY, USA). The assumption of normality was assessed using statistical methods. For all analyses, a p-value of 0.05 was considered statistically significant. Correlation of PA of patients with pneumoconiosis and each item was analyzed using Spearman's rank correlation coefficient. Multiple regression analysis (stepwise method) was performed to identify factors that independently affect PA. The data were then path-analyzed using SPSS Amos (Version 26.0 for Windows; IBM Corporation, Armonk, NY, USA). This analysis efficiently and directly allows for the simultaneous modeling and testing of indirect or mediated associations among variables. Figure 1 shows a hypothetical model based on previous research. The hypothetical model was modified based on the results of the correlation and multiple regression analyses, and path analysis was performed to examine suitability.

\section{Results}

Five hundred people who were scheduled to undergo a pneumoconiosis health examination at Asahi Rosai Hospital were considered for this study. Of these, 123 were excluded based on the exclusion criteria and 377 were included. The number of respondents was 185 (men: 171, women: 14), and the response rate was $50.4 \%$. The participants' characteristics are presented in Table 1.

Table 1

Characteristics of participants $(n=185)$

\begin{tabular}{|ll|}
\hline Sex (men/women) & $171 / 14$ \\
\hline Age (years) & $78.5 \pm 6.1$ \\
\hline Pneumoconiosis Supervision Class $(2 / 3 / 4)$ & $129 / 48 / 8$ \\
\hline Data are shown as mean \pm SD for those with normal distribution \\
\hline Abbreviations: SD, Standard deviation;
\end{tabular}

The results on personal factors and subjective symptoms are shown in Table 2 . Ninety percent $(n=167)$ had no experience of pulmonary rehabilitation, and $75 \%(n=138)$ were unaware of pulmonary rehabilitation. Regarding subjective symptoms, $54 \%(n=100)$ had dyspnea of mMRC grade 1 or higher. The results on the physical activity, psychological factors, and environmental factors are shown in Table 3. Regarding PA, $47 \%(n=86)$ were in the low activity group. For the stage of change, $65 \%(n=121)$ were 
at the action and maintenance stage and regularly performed PA.

Table 2

Personal factors and subjective symptoms of participants $(n=185)$

\section{Personal factors}

Pulmonary rehabilitation experience (Yes / No)

$18 / 167$

Pulmonary rehabilitation recognition

52 / $86 / 11 / 23$ /

(I do not know at all / I do not know much / I cannot say either / I know a little /

13

I know well)

Smoking history

$8 / 128 / 62$

(current-smoker / former-smoker / non-smoker)

\section{Subjective symptoms}

Dyspnea (mMRC Grade 0 / 1 / 2 / 3 / 4)

$85 / 53 / 35 / 10 /$

2

QOL (CAT 0-40 points)

$11(18-6)$

Notes: Shown as mean median (75\%-25\%) for non-normally distributed data

Abbreviations: mMRC, modified Medical Research Council; CAT, COPD assessment test 
Table 3

Physical activity, psychological, and environmental factors ( $\mathrm{n}=185$ )

\section{Physical activities}

IPAQ

Total score (Mets $\square$ minutes/week)

$876(2970-198)$

Category Classification (Low / Moderate / High)

$86 / 52$ / 47

\section{Psychological factors}

SDS (20-80 points)

$49(52-44)$

Stage of Change

49 / 9 / 6 / 12 / 109

(precontemplation, contemplation, preparation, action, maintenance)

SE (6-30 points)

$14(18-10)$

OE (9-45 points)

$31(35-27)$

DB (-20-20 points)

$3(6-0)$

\section{Environmental factors}

IPAQ-E (7-28 points)

$18(20-15)$

LSA (0-120 points)

$96(114-76)$

Notes: Shown as mean median (75\%-25\%) for non-normally distributed data

Abbreviations: IPAQ, International Physical Activity Questionnaire; SDS, Self-rating Depression Scale; SE, Self-efficacy; OE, Outcome expectations; DB, Decisional balance; IPAQ-E, International Physical Activity Questionnaire- Environment; LSA, Life Space Assessment;

The results of the correlation analyses are shown in Table 4. PA was significantly correlated with age, dyspnea (mMRC), stage of change, SE, OE, QOL (CAT), depression (SDS), DB, and living space (LSA). 
Table 4

Correlation between physical activity and scale scores $(n=185)$

\begin{tabular}{|lll|}
\hline Variables & $\mathbf{r}$ & $\mathbf{p}$-value \\
\hline Age & -0.26 & $0.000 * *$ \\
\hline Dyspnea (mMRC) & -0.34 & $0.000 * *$ \\
\hline QOL(CAT) & -0.33 & $0.000 * *$ \\
\hline IPAQ-E & 0.14 & 0.052 \\
\hline LSA & 0.31 & $0.000 * *$ \\
\hline SDS & -0.15 & 0.037 * \\
\hline Stage of change & 0.43 & $0.000 * *$ \\
\hline SE & 0.33 & $0.000 * *$ \\
\hline OE & 0.36 & 0.000 ** \\
\hline DB & 0.19 & 0.010 * \\
\hline $\begin{array}{l}\text { Spearman correlation (r), *p < 0.05, **p < 0.01 } \\
\text { Abbreviations: mMRC, modified Medical Research Council; CAT, COPD assessment test; IPAQ-E, }\end{array}$ \\
\hline $\begin{array}{l}\text { International Physical Activity Questionnaire- Environment; LSA, Life Space Assessment; SDS, Self- } \\
\text { rating Depression Scale; SE, Self-efficacy; OE, Outcome expectations; DB, Decisional balance; }\end{array}$ \\
\hline
\end{tabular}

The results of the multiple regression analysis are presented in Table 5. Multiple regression analysis was performed using PA as the dependent variable and items significant in the correlation analysis as independent variables. OE and dyspnea were the independent factors in the multiple regression analysis. The model was statistically significant $(p<0.05)$ and explained $20 \%$ of the variance in PA (adjusted R2 = $0.20)$. The standardized beta coefficients indicated that both $\mathrm{OE}(\beta=0.25, p<0.05)$ and dyspnea $(\beta=-$ $0.15, p<0.05)$ were associated with PA. 
Table 5

Results of multiple regression analyses with mean daily physical activity as the dependent variable.

\begin{tabular}{|c|c|c|c|c|c|c|}
\hline & \multicolumn{2}{|c|}{$\begin{array}{l}\text { Unstandardized } \\
\text { coefficient }\end{array}$} & \multirow{2}{*}{$\begin{array}{l}\text { Standardized } \\
\text { B }\end{array}$} & \multirow[t]{2}{*}{ p-value } & \multirow[t]{2}{*}{$\mathrm{R}^{2}$} & \multirow[t]{2}{*}{$\mathrm{R}^{2}$-Change } \\
\hline & $B$ & SE & & & & \\
\hline (Constant) & -1421.4 & 1443.5 & & & & \\
\hline OE & 141.0 & 39.8 & 0.26 & 0.001 & & \\
\hline \multirow[t]{2}{*}{$\mathrm{mMRC}$} & -537.4 & 198.9 & -0.20 & 0.008 & & \\
\hline & & & & & 0.20 & \\
\hline
\end{tabular}

The path analysis results are shown in Figure 2. The path model represented an excellent fit for the data. $\mathrm{OE}$ (standardized estimate $=0.26$ ) and dyspnea (standardized estimate $=-0.20$ ) had a direct effect on PA. SE and DB indirectly affected PA through the OE. Furthermore, dyspnea did not only affect PA, but also affected the standardized estimates of $\mathrm{OE}(-0.17)$, stage of change $(-0.12), \mathrm{QOL}(0.50)$, living space $(-0.26)$, and depression (0.34) directly.

\section{Discussion}

The purpose of this study was to clarify the relationship between PA and psychological and environmental factors in patients with pneumoconiosis. We were able to ascertain the comprehensive relationship between them by conducting a path analysis.

Regarding psychological factors, OE directly affected PA. SE and DB indirectly affected PA, with OE as a mediating factor.

The association between PA and psychological factors in patients with CRD has been reported to be associated with SE [26, 27]. SE represents confidence in performing an exercise [13]. SE has been reported to be associated with PA not only in patients with CRD, but also in a variety of subjects, including healthy elderly persons and patients with diabetes. Therefore, it is assumed that behavior change is dependent on SE [13]. In this study, SE was correlated and associated with PA. This result is similar to those in previous reports. However, the psychological factor that had a direct impact on PA was OE. OE is an understanding of the benefits of PA and the associated expectations. In TTM, it is considered a factor that mediates behavioral change [13]. It has been reported that OE is related to PA in healthy elderly people and patients with chronic disease [28-31]. The lack of knowledge about the appropriate PA to perform may explain why OE had more impact on PA than SE. Most of the subjects in this study were in the action or maintenance stage of behavior change and reported that they exercised habitually. However, the PA determined by the IPAQ classified them in the low-activity group. In other words, there was a 
difference between subjective exercise and actual PA. Therefore, it is likely that $\mathrm{OE}$, which represents the understanding of PA, was more influential than SE, which represents confidence in performing PA. One possible reason for the lack of knowledge about the required PA is the low implementation rate of pulmonary rehabilitation. The rate of implementation of pulmonary rehabilitation among the subjects in this study was lower than that reported for home-based patients with COPD in Japan [32]. Thus, it is assumed that patients with CRD have few opportunities to be educated on the importance, the required amount, and the intensity of PA.

Dyspnea is the most common symptom of CRD [33]. In patients with CRD, dyspnea is reported to be a fundamental symptom that limits PA because patients with dyspnea consciously or subconsciously avoid daily activities [34,35]. In addition, dyspnea has been reported to affect a variety of symptoms which may be elicited using a question-prompt list such as symptoms of depression. It has been empirically reported that dyspnea causes a vicious cycle of decreased activity and decreased physical function, resulting in further increases in dyspnea [18]. Recently, this vicious cycle has been demonstrated in patients with COPD using path analysis [36]. The results of the present study indicate that dyspnea directly affects PA in patients with pneumoconiosis, as it does in patients with other CRDs. Furthermore, the results of the path analysis showed that dyspnea not only affected PA, but also impacted many other health-related items, such as depression and QOL. Hence, dyspnea was found to be a fundamental factor affecting PA and many other health-related items in patients with pneumoconiosis. Pulmonary rehabilitation has been reported to improve dyspnea in patients with CRD such as COPD and IP [18, 37]. The results of this study also show that pulmonary rehabilitation can improve dyspnea in pneumoconiosis patients, which may also improve QOL and other symptoms.

There was a significant correlation between LSA and PA when environmental factors were evaluated. LSA has been reported to be associated with PA in the elderly, and the results were similar to those of previous studies [38, 39]. However, the environment surrounding the home (IPAQ-E) was not associated with PA in this study.

The environment around the home has been reported to be associated with PA and the number of steps in healthy elderly people and patients with various diseases such as knee and hip Osteoarthritis (OA) [24, 40-42]. In this study, unlike in previous reports on elderly persons, there was no relationship between PA and the home environment. This may be a unique trend in patients with respiratory disease. This means that patients with respiratory diseases may decrease their PA if they have strong subjective symptoms (dyspnea), regardless of the environment around their home. In patients with OA of the knee or hip, PA has been reported to be associated with the environment surrounding the home, but the influence of physical factors such as pain was stronger [42]. It was believed that subjective symptoms (dyspnea) may have an even stronger influence on PA in patients with respiratory diseases than in patients with other diseases.

We previously reported that elderly patients with pneumoconiosis have greater lower limb muscle strength than healthy elderly patients, even when PA is similar, and that pulmonary rehabilitation is 
necessary. The results of this study also suggest that pulmonary rehabilitation is necessary for patients with pneumoconiosis. Pulmonary rehabilitation has been reported to improve dyspnea [43]. However, improvement of dyspnea alone is not sufficient to improve PA, and patient education on psychological factors is also important. Until now, patient education in pulmonary rehabilitation has often focused on SE. OE is a prerequisite for behavioral change, and it is believed that both SE and OE need to be improved in order for behavioral change to occur [44]. Therefore, $\mathrm{OE}$ is a psychological factor that should be incorporated into intervention programs aimed at promoting physical activity $[44,45]$. Therefore, in addition to conventional pulmonary rehabilitation, patient education is needed to improve OE and patient understanding of PA.

\section{Conclusion}

Dyspnea and OE were associated with PA in patients with pneumoconiosis. To improve the PA of patients with pneumoconiosis, it is necessary to reduce dyspnea and promote an understanding of PA.

\section{Abbreviations}

CAT: COPD Assessment Test

COPD: chronic obstructive pulmonary disease

CRD: chronic respiratory disease

DB: decisional balance

IP: interstitial pneumonia

IPAQ: International Physical Activity Questionnaire

IPAQ-E: International Physical Activity Questionnaire-Environment

LSA: life space assessment

mMRC: modified Medical Research Council

OE: outcome expectations

PA: physical activity

QOL: quality of life

SE: self-efficacy

TTM: transtheoretical model 


\section{Declarations}

\section{Ethics approval and consent to participate}

The study was approved by the Bioethics Committee of Nagoya University (approval number: 18-515) and the Ethics Committee of Asahi Rosai Hospital (2019.3). All patients provided informed consent.

\section{Consent for publication}

Not applicable

\section{Availability of data and materials}

The data that support the findings of this study are available from the corresponding author, Yasushi Uchiyama, upon reasonable request.

\section{Competing interests}

The authors declare that they have no competing interests

\section{Funding}

This study was supported by research funds to promote the hospital functions of the Japan Organization of Occupational Health and Safety.

\section{Authors' contributions}

TK conceived and designed the study, acquired, analyzed, and interpreted the data, and drafted the manuscript. TH designed the study, analyzed, and interpreted the data. YU revised the manuscript critically for important intellectual content. All authors read and approved the final manuscript.

\section{Acknowledgments}

The authors acknowledge the Director of Asahi Rosai Hospital and the Head of the Department of Respiratory Medicine for their support of our research. This research was supported by research funds to promote the hospital functions of the Japan Organization of Occupational Health and Safety.

\section{References}

1. Cullinan P, Reid P. Pneumoconiosis. Prim Care Respir J. 2013;22:249-52.

2. Ministry of Health L and W. Pneumoconiosis law. Law No. 30 of March 31, 1960. http://law.egov.go.jp/htmldata/S35/S35H0030.html (in Japanese). Accessed 17 Sept 2019.

3. Vestbo J, Hurd SS, Agustí AG, Jones PW, Vogelmeier C, Anzueto A, et al. Global strategy for the diagnosis, management, and prevention of chronic obstructive pulmonary disease: GOLD executive 
summary. Am J Respir Crit Care Med. 2013;187:347-65.

4. Nishiyama O, Yamazaki R, Sano H, Iwanaga T, Higashimoto Y, Kume H, et al. Physical activity in daily life in patients with idiopathic pulmonary fibrosis. Respir Investig. 2018;56:57-63.

5. Waschki B, Kirsten A, Holz O, Müller KC, Meyer T, Watz H, et al. Physical activity is the strongest predictor of all-cause mortality in patients with COPD: A prospective cohort study. Chest. 2011;140:331-42.

6. Bahmer T, Kirsten AM, Waschki B, Rabe KF, Magnussen H, Kirsten D, et al. Prognosis and longitudinal changes of physical activity in idiopathic pulmonary fibrosis. BMC Pulm Med. 2017;17:104.

7. Ueki J, Kozu R. Pulmonary Rehabilitation in Japan: A position statement from the Japan Society for Respiratory Care and Rehabilitation, the Japanese Society of Respiratory Physical Therapy, and the Japanese Respiratory Society. J Jpn Soc Respir Care Rehabil. 2018;27:95-114.

8. Tödt K, Skargren E, Jakobsson P, Theander K, Unosson M. Factors associated with low physical activity in patients with chronic obstructive pulmonary disease: A cross-sectional study. Scand J Caring Sci. 2015;29:697-707.

9. Prochaska JO. In search of how people change. Applications to addictive behaviors. Am Psychol. 1992;47:1102-14.

10. Bauman AE, Reis RS, Sallis JF, Wells JC, Loos RJF, Martin BW, et al. Correlates of physical activity: Why are some people physically active and others not? Lancet. 2012;380:258-71. doi:10.1016/S0140-6736(12)60735-1.

11. Salman A, Ukwaja KN, Alkhatib A. Factors associated with meeting current recommendation for physical activity in scottish adults with diabetes. Int J Environ Res Public Health. 2019;16

12. Tadaki S, Sakata Y, Miura Y, Nochioka K, Miura M, Miyata S, et al. Factors limiting habitual exercise in patients with chronic heart failure: a multicenter prospective cohort study. Heart Vessels. 2020;35:655-64. doi:10.1007/s00380-019-01529-4.

13. Prochaska JO. In search of how people change. Applications to addictive behaviors. Am Psychol. 1992;47:1102-14.

14. Svetkey LP, Harsha DW, Vollmer WM, Stevens VJ, Obarzanek E, Elmer PJ, et al. Premier: A clinical trial of comprehensive lifestyle modification for blood pressure control: rationale, design and baseline characteristics. Ann Epidemiol. 2003;13:462-71.

15. Clark PG, Nigg CR, Greene G, Riebe D, Saunders SD. The Study of Exercise and Nutrition in Older Rhode Islanders (SENIOR): Translating theory into research. Health Educ Res. 2002;17:552-61.

16. Kirk A, MacMillan F, Webster N. Application of the Transtheoretical model to physical activity in older adults with Type 2 diabetes and/or cardiovascular disease. Psychol Sport Exerc. 2010;11:320-4. doi:10.1016/j.psychsport.2010.03.001.

17. Gimeno-Santos E, Frei A, Steurer-Stey C, De Batlle J, Rabinovich RA, Raste Y, et al. Determinants and outcomes of physical activity in patients with COPD: a systematic review. Thorax. 2014; doi:10.1136/thoraxjnl-2013-204763. 
18. Global Initiative for Chronic Obstructive Lung Disease. Global strategy for the diagnosis, management, and prevention of chronic obstructive pulmonary disease 2020 REPORT. 2020. https://goldcopd.org/wp-content/uploads/2019/12/GOLD-2020-FINAL-ver1.2-03Dec19_WMV.pdf. Accessed 27 Oct 2021.

19. Jones PW, Harding G, Berry P, Wiklund I, Chen WH, Kline Leidy N. Development and first validation of the COPD Assessment Test. Eur Respir J. 2009;34:648-54.

20. Ipaq. Guidelines for data processing and analysis of the International Physical Activity Questionnaire (IPAQ) - Short and Long Forms. Ipaq. 2005;November:1-15.

21. Nigg CR, Riebe DF, Rossi JS, Stillwell KM, Garber CE, Burbank PM, et al. Do the transtheoretical model instruments for exercise behavior apply to older adults? Med Sci Sport Exerc. 2001;33:149.

22. Patricia M. Burbank, Riebe D, Takenaka K. Promoting Exercise and Behavior Change in Older Adults: Interventions With the Transtheoretical Model. In: Book House HD, Ltd. 2002.

23. Resnick B, Zimmerman SI, Orwig D, Furstenberg AL, Magaziner J. Outcome expectations for exercise scale: utility and psychometrics. J Gerontol B Psychol Sci Soc Sci. 2000;55:352-6.

24. Inoue S, Murase N, Shimomitsu T, Ohya Y, Odagiri Y, Takamiya T, et al. Association of physical activity and neighborhood environment among Japanese adults. Prev Med. 2009;48:321-5.

25. Peel C, Baker PS, Roth DL, Brown CJ, Bodner E V., Allman RM. Assessing mobility in older adults: The UAB study of aging life-space assessment. Phys Ther. 2005;85:1008-119.

26. Altenburg WA, Bossenbroek L, De Greef MHG, Kerstjens HAM, Ten Hacken NHT, Wempe JB. Functional and psychological variables both affect daily physical activity in COPD: A structural equations model. Respir Med. 2013;107:1740-7.

27. Hartman JE, Boezen HM, de Greef MH, Ten Hacken NH. Physical and psychosocial factors associated with physical activity in patients with chronic obstructive pulmonary disease. Arch Phys Med Rehabil. 2013;94(12):2396-2402.e7.

28. Resnick B, Nahm ES, Zhu S, Brown C, An M, Park B, et al. The impact of osteoporosis, falls, fear of falling, and efficacy expectations on exercise among community-dwelling older adults. Orthop Nurs. 2014;33:277-86.

29. Lorig K, Chastain RL, Ung E, Shoor S, Holman HR. Development and evaluation of a scale to measure perceived self-efficacy in people with arthritis. Arthritis Rheum. 1989;32:37-44.

30. Goossens MEJB, Vlaeyen JWS, Hidding A, Kole-Snijders A, Evers SMAA. Treatment expectancy affects the outcome of cognitive-behavioral interventions in chronic pain. Clin J Pain. 2005;21:1826.

31. Marszalek J, Price LL, Harvey WF, Driban JB, Wang C. Outcome expectations and osteoarthritis: association of perceived benefits of exercise with self-efficacy and depression. Arthritis Care Res. 2017;69:491-8.

32. The Japanese Respiratory Society, The respiratory failure Research Group from the Ministry of Health, Labour, and Welfare J. In: White paper on home respiratory care 2010. 2013.. http://www.jrs.or.jp/uploads/uploads/files/photos/1096.pdf. Accessed 27 Oct 2021. 
33. Blinderman CD, Homel P, Billings JA, Tennstedt S, Portenoy RK. Symptom distress and quality of life in patients with advanced chronic obstructive pulmonary disease. J Pain Symptom Manage. 2009;38:115-23.

34. Kurosawa H. Approaches for pulmonary rehabilitation to improve daily physical activity. J Jpn Soc Respir Care Rehabil. 2017;26:451-5.

35. Troosters T, Van Der Molen T, Polkey M, Rabinovich RA, Vogiatzis I, Weisman I, et al. Improving physical activity in COPD: towards a new paradigm. Respir Res. 2013;14:115.

36. Ramon MA, Ter Riet G, Carsin AE, Gimeno-Santos E, Agustí A, Antó JM, et al. The dyspnoeainactivity vicious circle in COPD: development and external validation of a conceptual model. Eur Respir J. 2018;52.

37. Dowman LM, McDonald CF, Hill CJ, Lee AL, Barker K, Boote C, et al. The evidence of benefits of exercise training in interstitial lung disease: a randomised controlled trial. Thorax. 2017;72:610-9.

38. Tsai LT, Rantakokko M, Rantanen T, Viljanen A, Kauppinen M, Portegijs E. Objectively measured physical activity and changes in life-space mobility among older people. J Gerontol A Biol Sci Med Sci. 2016;71:1466-71.

39. Seinsche J, Zijlstra W, Giannouli E. Motility in frail older adults: operationalization of a new framework and first insights into its relationship with physical activity and life-space mobility: an exploratory study. Int J Environ Res Public Health. 2020;17:1-20.

40. Barnett DW, Barnett A, Nathan A, Van Cauwenberg J, Cerin E. Built environmental correlates of older adults' total physical activity and walking: A systematic review and meta-analysis. Int $\mathrm{J}$ Behav Nutr Phys Act. 2017;14:103.

41. Moran M, Van Cauwenberg J, Hercky-Linnewiel R, Cerin E, Deforche B, Plaut P. Understanding the relationships between the physical environment and physical activity in older adults: A systematic review of qualitative studies. Int J Behav Nutr Phys Act. 2014;11:79.

42. Stubbs B, Hurley M, Smith $\mathrm{T}$. What are the factors that influence physical activity participation in adults with knee and hip osteoarthritis? A systematic review of physical activity correlates. Clin Rehabil. 2015;29:80-94.

43. Spruit MA, Singh SJ, Garvey C, Zu Wallack R, Nici L, Rochester C, et al. An official American Thoracic Society/European Respiratory Society statement: key concepts and advances in pulmonary rehabilitation. Am J Respir Crit Care Med. 2013;188.

44. Bandura A. Self-efficacy: The exercise of control. New York: W.H. Freeman and Company. Am Psychol Assoc. 1997;23:604.

45. Williams DM, Anderson ES, Winett RA. A review of the outcome expectancy construct in physical activity research. Ann Behav Med. 2005;29:70-9.

\section{Figures}




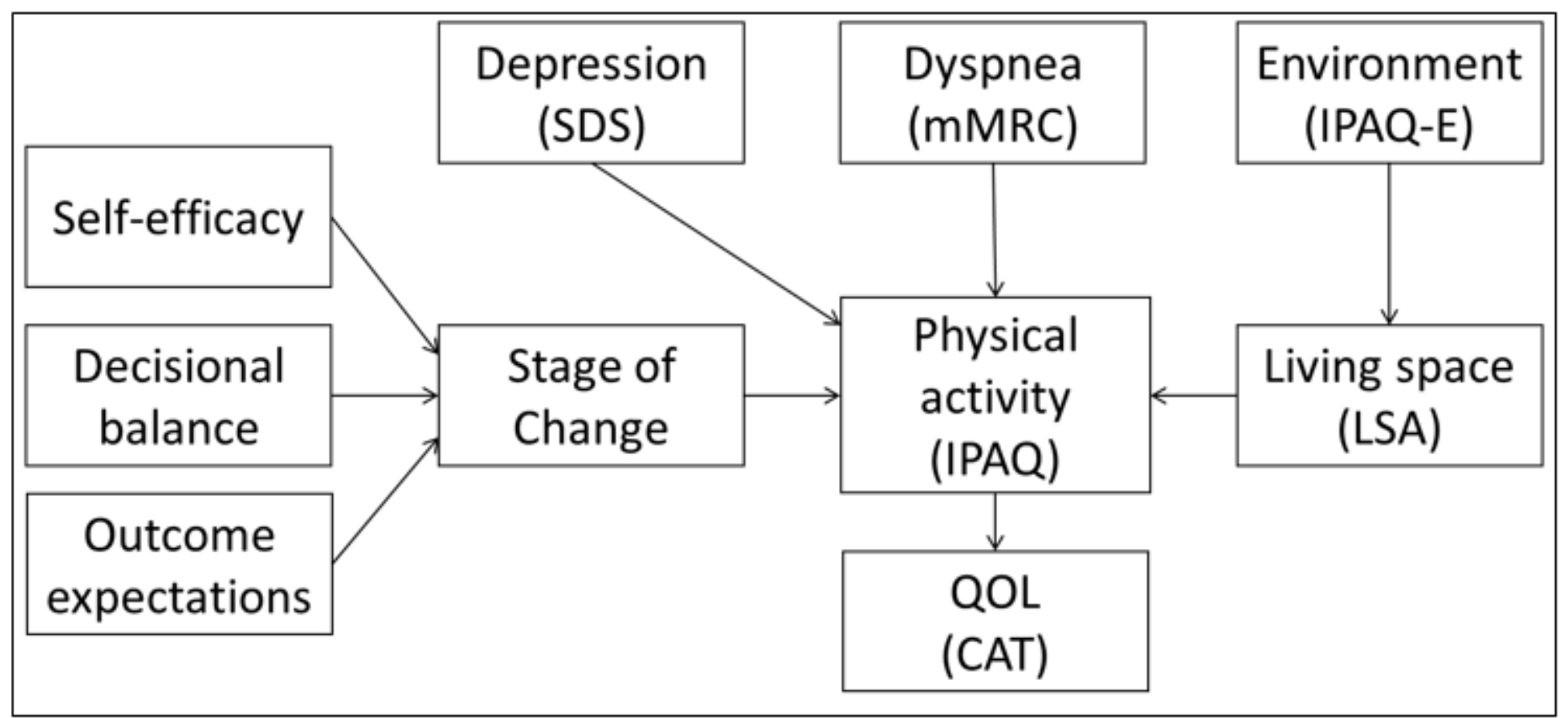

Figure 1

Hypothesized model

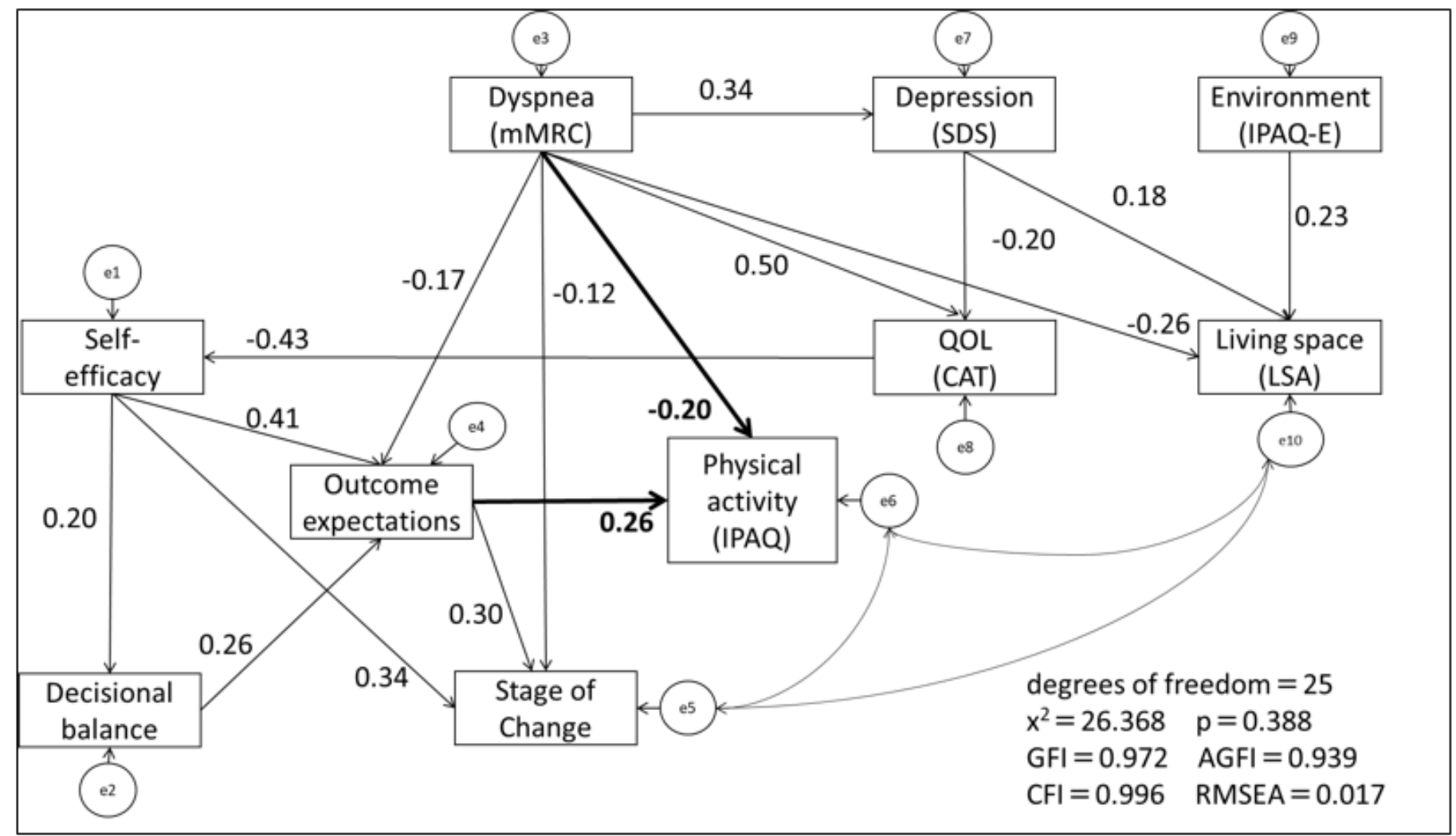

Figure 2 
Final model and path coefficients The strength of this relationship is shown by the path coefficient (standardized regression coefficient). 